Opinion

\title{
Change for hearing aids
}

\begin{abstract}
Increasing hearing aid market penetration through updating the term "hearing aids" can make an impact and improve qualities of life.
\end{abstract}

Keywords: audiology, hearing aids, depression
Volume 7 Issue 5 - 2017

John Malan

California State University, USA

Correspondence: John Malan California State University Northridge 181 I I Nordhoff St Northridge CA 91330, USA, Te 8|8-731-II78,Email john.malan@csun.edu

Received: June 15, 2017 | Published: June 19,2017

\section{Opinion}

In the profession of audiology, dispensing hearing aids is an important way that we help others and improve their quality of life. Untreated hearing loss has numerous negative psychological effects; from anxiety and seclusion to depression (NCOA, 1999). So why do so many people who have a sensorineural hearing loss just decide to not do anything about it? Certainly money can be a factor (hearing aids average about $\$ 2000$ each) as can poor word-of-mouth from people who've had bad experiences. In the U.S. the hearing aid market penetration rate has hovered around $23 \%$ for decades despite exponential technological improvements to size, sound quality and background noise reduction. In Europe where socialized medicine covers all or the majority of the cost, their penetration rate is around $40 \%$.

My theory to improve market penetration is quite simple, get rid of the name "hearing aids" and update it with something modern. Many people are ignorant to the incredible technology that goes into amplification. There are six major manufacturers of hearing aids that EACH spend in the range of \$100million A YEAR on research and development and most people think hearing aids are the huge BehindThe-Ear aids that grandpa wore in the 1970s that randomly whistled and didn't help a whole lot. Today's hearing aids have GPS, iPhone and Android compatibility, Internet access and many accessories to combat background noise and significantly improve signal-to-noise ratios. They're cosmetically appealing and can be rechargeable which very earth is friendly since a few hundred million batteries annually end up in landfills.

So what's a good name change instead of the archaic "hearing aid?" Auditory Enhancers? Audiunts (Latin for hearing)? Audibles? The Baby Boomers arrived in our offices in January 2011 at rate of 10,000 per day for nineteen years. This group is informed and is different from previous generations. A little creative marketing and smoke and mirrors might change some lives.

\section{Acknowledgments}

None.

\section{Conflicts of interest}

Author declares there are no conflicts of interest.

\section{Funding}

None. 